\title{
Penampilan Tanaman Krisan Pot (Dendranthema grandiflora) Akibat Retardan dan Pemangkasan Pucuk
}

\section{The Performance of Potted Chrysanthemum (Dendranthema grandiflora) Due to Growth Retardant and Terminal Bud Pinching}

\author{
Nugraheni Widyawati
}

Diterima 02 Februari 2019/Disetujui 18 Juni 2019

\begin{abstract}
The research of the effects of retardant and terminal bud pinching on the performance of potted chrysanthemum was conducted using the Randomized Block Design, consist of seven treatments and four replications. The treatments were P1) control without retardant and bud pinching; P2) Retardant at transplanting into pots; P3) Retardant at one week after transplanting; P4) Retardant at two weeks after transplanting; P5) Pinching at the time of transplanting; P6) Pinching at one week after transplanting; P7) Pinching at two weeks after transplanting. Experimental data were analyzed using ANOVA and the analysis of the differences among treatments used Honest Significant Different (HSD) with $\alpha=5 \%$. The results showed that retardant increased the chlorophyl of leaf, reduced the height of plant and diameter of shoot, reduced the number and diameter of flowers. Pinching decreased the height of shoot, increase the number of flowers. Retardant and pinching treatment did not cause the anthesis simultaneously. The performance of chrysanthemum pots on retardant treatment is more ideal than control and terminal bud pinching treatment.
\end{abstract}

Keywords: chrysanthemum, flowering, growth, paclobutrazol, pinching

\begin{abstract}
ABSTRAK
Kajian pengaruh perlakuan retardant dan pemangkasan pucuk terhadap penampilan tanaman krisan pot (Dendranthema grandiflora) dilakukan menggunakan Rancangan Acak Kelompok yang terdiri atas tujuh perlakuan dengan empat ulangan, yaitu: P1) Kontrol tanpa retardan dan pemangkasan pucuk; P2) Penyemprotan retardan saat pindah tanam bibit; P3) Penyemprotan retardan 1 minggu setelah pindah tanam bibit; P4) Penyemprotan retardan 2 minggu setelah pindah tanam bibit; P5) Pemangkasan pucuk saat pindah tanam bibit; P6). Pemangkasan pucuk 1 minggu setelah pindah tanam bibit; P7) Pemangkasan pucuk 2 minggu setelah pindah tanam bibit. Data hasil penelitian dianalisis menggunakan ANOVA dan BNJ 5\%. Hasil penelitian menunjukkan bahwa retardan meningkatkan kandungan klorofil daun, tanaman menjadi lebih pendek, diameter tajuk lebih kecil, jumlah bunga per pot lebih sedikit dan diameter bunga lebih kecil. Pemangkasan pucuk menurunkan tinggi tanaman, meningkatkan jumlah bunga per tanaman dan jumlah bunga per pot. Perlakuan retardan dan pemangkasan pucuk menyebabkan mekarnya bunga kurang serempak. Penampilan krisan pot dengan perlakuan retardan lebih ideal dibandingkan kontrol dan pemangkasan pucuk.
\end{abstract}

Kata kunci : pembungaan, pertumbuhan, krisan pot, paclobutrazol, pemangkasan pucuk 


\section{PENDAHULUAN}

Tanaman krisan (Dendranthema grandiflora) dibudidayakan dengan dua tujuan yaitu sebagai bunga potong (cut flowers) dan sebagai tanaman pot. Hasil studi Pratomo dan Andri (2013) tentang agribisnis bunga krisan di Kabupaten Pasuruan, Jawa Timur, menunjukkan bahwa walaupun pemasaran bunga krisan masih mengandalkan pasar lokal, namun pengembangan agribisnis komoditas ini sangat bermanfaat bagi perekonomian masyarakat dan daerah karena membuka kesempatan kerja dan usaha.

Krisan pot dikenal sebagai bahan dekorasi taman di dalam ruang (indoor) dan di luar ruangan (outdoor). Sebagai elemen dekorasi, krisan pot disukai karena mudah dipindah, ditata dan kesegaran bunganya relatif lama bahkan bisa ditampilkan lebih dari satu bulan. Sebagai tanaman pot, keunggulan produk ini terletak pada penampilannya, meskipun belum ada kriteria baku yang digunakan sebagai standar penilaian penampilannya. Konsumen menilai produk ini antara lain dari aspek keserempakan munculnya bunga, keseimbangan tajuk dengan pot, kesehatan tanaman dan kecerahan warna bunga.

Prospek tanaman krisan pot dalam perdagangan tanaman hias cukup bagus, seiring dengan meningkatnya animo masyarakat untuk memperindah lingkungannya. Menurut Nurmalinda dan Hayati (2014), permintaan bunga krisan baik sebagai bunga potong maupun bunga pot di dalam negeri dari tahun ke tahun menunjukkan kecenderungan makin meningkat. Pernyataan tersebut didukung pula oleh Hayati et al. (2018) yang menyatakan bahwa potensi budidaya krisan sebagai bisnis florikultura masih tetap diminati oleh kalangan pelaku usaha dalam kurun waktu yang relatif panjang, karena permintaan pasar dalam dan luar negeri masih sangat tinggi dibandingkan dengan tanaman hias lain.

Datta (2012) menyatakan bahwa tanaman krisan termasuk dalam kelompok tanaman hari pendek (short day plant). Hasil penelitian Sajid et al. (2016) pada tanaman krisan menunjukkan bahwa fotoperiode 9 dan 10.5 jam per hari menyebabkan pembungaan yang terbaik.

Dalam budidaya tanaman krisan pot, sangat penting untuk mengatur tinggi tanaman, arah percabangan dan tajuk tanaman agar proporsional dengan ukuran potnya. Sejauh ini dikenal dua teknik untuk mengendalikan tinggi tanaman yaitu melalui pemangkasan dan retardan. Hasil penelitian Nurrahmadani dan Irawati (2017) menggunakan retardan dengan bahan aktif 2.2-dimethylhydrazide 1000 ppm, menunjukkan bahwa aplikasi zat penghambat tersebut dapat menekan pertumbuhan tinggi tanaman krisan pot secara nyata. Hasil penelitian Pobudkiewicz (2014) pada krisan pot, menunjukkan bahwa dibandingkan dengan kontrol, pemberian retardan konsentrasi $7.5 \mathrm{mg}$ $\mathrm{L}^{-1}$ pada kultivar "Jewel Time" dan "Kodiak" menyebabkan pemendekan tanaman sebesar 41\% dan $25 \%$.

Pemangkasan berfungsi untuk memperbanyak percabangan pada tanaman krisan, sehingga kuntum bunga yang dihasilkan menjadi banyak. Dalam budidaya krisan pot, perlakuan pemangkasan dan pemberian retardan sudah cukup dikenal, namun masih banyak pertanyaan yang belum terjawab tentang respon tanaman krisan terhadap perlakuan tersebut dan banyak pula praktisi yang memerlukan petunjuk praktis berkaitan dengan teknik memproduksi krisan pot. Tujuan percobaan ini adalah untuk mengetahui pengaruh waktu pemberian retardan dan pemangkasan pucuk terhadap penampilan tanaman krisan pot kultivar Fiji berwarna Pink.

\section{BAHAN DAN METODE}

Percobaan dilakukan di kebun Fakultas Pertanian dan Bisnis Universitas Kristen Satya Wacana di kota Salatiga, terletak pada elevasi 540 meter di atas permukaan laut (m dpl) dengan suhu udara $22-28{ }^{\circ} \mathrm{C}$, pada bulan Juni sampai Oktober 2017. Percobaan dilakukan dalam greenhouse beratap plastik UV dengan penerusan cahaya matahari (70-80)\%. Tanaman krisan ditanam dalam pot plastik hitam berdiameter $18 \mathrm{~cm}$, tinggi $14 \mathrm{~cm}$ diletakkan di atas rak bambu. Percobaan menggunakan Rancangan Acak Kelompok dengan tujuh perlakuan yaitu: kontrol tanpa perlakuan retardan dan pemangkasan pucuk (P1); Pemberian retardan saat pindah tanam bibit (P2); Pemberian retardan 1 minggu setelah pindah tanam bibit (P3); Pemberian retardan 2 minggu setelah pindah tanam bibit (P4); Pemangkasan pucuk saat pindah tanam bibit (P5); Pemangkasan pucuk 1 minggu setelah 
pindah tanam bibit (P6); Pemangkasan pucuk 2 minggu setelah pindah tanam bibit (P7). Setiap perlakuan diulang empat kali, setiap ulangan terdiri dari 10 pot, sehingga terdapat 280 unit pengamatan dan masing-masing pot berisi 5 tanaman.

Pengamatan utama meliputi kandungan klorofil daun (diukur menggunakan Chlorophyll Meter SPAD 502-Plus); tinggi tanaman saat bunga pertama mekar penuh; rasio tinggi krisan pot dengan tinggi pot; diameter tajuk saat bunga pertama mekar penuh; rasio tinggi tanaman dengan diameter tajuk; jumlah kuntum bunga per tanaman dan jumlah kuntum bunga per pot; diameter bunga mekar penuh; rasio jumlah bunga mekar dengan jumlah kuntum bunga per pot. Data hasil pengamatan dianalisis menggunakan analisis sidik ragam dan uji lanjut dengan BNJ dengan tingkat kepercayaan $95 \%$.

Tahapan percobaan meliputi penyediaan bibit, pembuatan naungan, pembuatan para-para bambu, persiapan media tanam, pindah tanam bibit krisan, pemberian perlakuan, pengamatan dan analisis data. Bibit yang digunakan adalah tanaman krisan kultivar Fiji berwarna pink. Media tanam yang digunakan dalam percobaan adalah campuran tanah kebun, pupuk kandang dan arang sekam, dengan perbandingan 1:1:3. Tidak ada anjuran untuk melakukan sterilisasi media tanam dalam budidaya krisan pot, tetapi dalam percobaan ini untuk mengurangi serangan mikrobia dan gulma, media tanam direbus hingga airnya mendidih kemudian dikering anginkan. Pindah tanam dilakukan 14 hari setelah pembibitan, masing masing pot berisi lima bibit. Perlakuan retardan menggunakan Cultar (berbahan aktif Paklobutrazol $250 \mathrm{~g} \mathrm{~L}^{-1}$ ), diberikan dengan konsentrasi $2 \mathrm{cc} \mathrm{L}^{-1}$, sesuai rentang petunjuk pemakaian produk Cultar yaitu

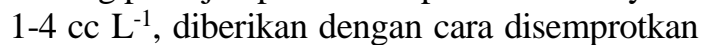
pada tajuk daun hingga basah selama dua hari berturut turut sekitar pukul 09.00 hingga 10.00. Pemangkasan pucuk dilakukan dengan memangkas tunas pucuk daun termuda. Pemeliharaan meliputi penyiraman, pemberian pupuk daun pada umur satu bulan setelah pindah tanam dan satu minggu setelah kuncup bunga keluar dengan konsentrasi $2 \mathrm{~g} \mathrm{~L}^{-1}$, pengendalian hama dan penyakit dilakukan secara mekanis dan menggunakan insektisida untuk mengendalikan ulat grayak, akarisida untuk mengendalikan thrips dan fungisida untuk megendalikan karat daun.

\section{HASIL DAN PEMBAHASAN}

Kandungan klorofil daun krisan pot diamati untuk memberikan gambaran fisik tentang warna daun. Pada Gambar 1. terlihat bahwa akibat perlakuan retardan, kandungan klorofil daun tanaman krisan pot lebih tinggi dibandingkan kontrol dan perlakuan pemangkasan pucuk, sehingga menyebabkan warna daun pada tanaman dengan perlakuan retardan lebih hijau dibandingkan tanaman dengan perlakuan lain. Percobaan ini membuktikan bahwa pemberian retardan mampu meningkatkan sintesis klorofil pada tanaman krisan pot.

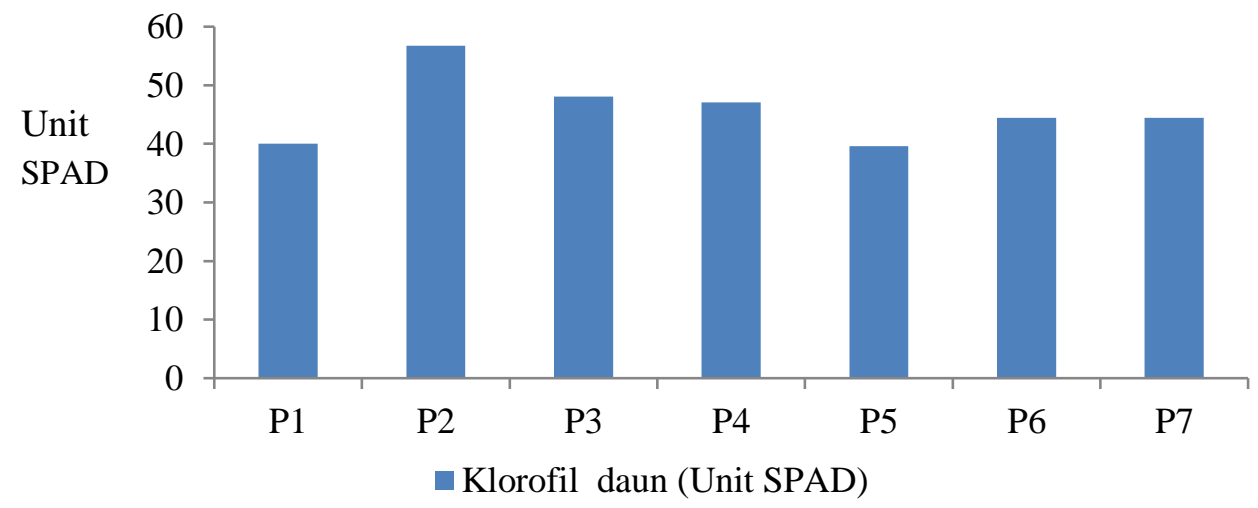

Keterangan: $\mathrm{P} 1=$ kontrol; $\mathrm{P} 2=$ Retardan saat pindah tanam; $\mathrm{P} 3=$ Retardan 1 minggu setelah pindah tanam; $\mathrm{P} 4=$ Retardan 2 minggu setelah pindah tanam; P5= Pemangkasan pucuk saat pindah tanam; P6= Pemangkasan pucuk 1 minggu setelah pindah tanam; P7= Pemangkasan pucuk 2 minggu setelah pindah tanam.

Gambar 1. Kandungan klorofil daun krisan pot pada berbagai perlakuan 
Pemberian retardan yang paling efektif dalam meningkatkan kandungan klorofil daun tanaman krisan pot adalah pada saat pindah tanam. Hal ini sesuai dengan hasil penelitian Nazarudin (2012) tentang efek retardan terhadap pertumbuhan dan pembungaan tanaman Hibiscus rosa-sinensis L. yang ditanam dalam pot, yang menunjukkan bahwa pemberian paclobutrazol meningkatkan kandungan klorofil sehingga daunnya terlihat lebih hijau.

Hasil analisis pengamatan tinggi tanaman, rasio antara tinggi krisan pot dengan tinggi pot, lingkar batang, diameter tajuk dan rasio antara tinggi tanaman dengan diameter tajuk disajikan dalam Tabel 1 .

Pada Tabel 1, terlihat bahwa baik pemberian retardan maupun pemangkasan pucuk, menyebabkan tinggi tanaman krisan pot menjadi lebih rendah secara nyata dibanding kontrol. Penghambatan pertumbuhan tinggi tanaman akibat pemberian retardan sebesar 57.7-61.5\%, sementara akibat perlakuan pemangkasan pucuk menghambat sebesar 12.8$14.5 \%$. Jika dibandingkan antara kedua perlakuan tersebut, ternyata pemberian retardan lebih efektif dalam menekan pertumbuhan tinggi tanaman dibandingkan perlakuan pemangkasan pucuk. Suhadi et al. (2017) dalam penelitiannya tentang efektifitas retardan sintetik terhadap pertumbuhan bunga matahari menyatakan bahwa retardan adalah suatu senyawa organik yang mampu menghambat pemanjangan batang, meningkatkan warna hijau daun dan secara tidak langsung memperngaruhi pembungaan, menghambat pembelahan dan pembesaran sel pada meristem sub-apikal tanpa menyebabkan pertumbuhan yang abnormal. Naidu et al. (2014) menyatakan bahwa efek peningkatan konsentrasi beberapa jenis retardan menyebabkan penurunan tinggi tanaman African Marigold (Tagetes erecta L.).

Kriteria ideal tinggi tanaman krisan pot pada umumnya adalah seimbang dengan ukuran tinggi pot. Ni'mah dan Sitawati (2018), menyatakan bahwa salah satu faktor penentu kualitas bunga krisan pot adalah keseimbangan antara tinggi tanaman dengan tinggi pot yang digunakan. Menurut Ramadhan et al. (2018), bahwa tinggi krisan pot yang ideal adalah sekitar 2 sampai 2.5 kali tinggi pot. Kurnia (2017) menyatakan bahwa pada krisan pot, tinggi tanaman diusahakan agar tampak ideal dengan tinggi pot yang digunakan yakni dengan tinggi tanaman sekitar $24-35 \mathrm{~cm}$.

Tabel 1. Pengaruh pemberian retardan dan pemangkasan pucuk terhadap tinggi tanaman, rasio tinggi krisan pot per tinggi pot, lingkar batang, diameter tajuk dan rasio tinggi tanaman per diamater tajuk tanaman krisan pot

\begin{tabular}{|c|c|c|c|c|c|}
\hline Perlakuan & $\begin{array}{l}\text { Tinggi } \\
\text { Tanaman } \\
(\mathrm{cm})\end{array}$ & $\begin{array}{l}\text { Rasio } \\
\text { Tinggi } \\
\text { krisan } \\
\text { pot per } \\
\text { tinggi pot }\end{array}$ & $\begin{array}{l}\text { Lingkar } \\
\text { Batang } \\
\text { (cm) }\end{array}$ & $\begin{array}{l}\text { Diameter } \\
\text { Tajuk } \\
\text { (cm) }\end{array}$ & $\begin{array}{c}\text { Rasio } \\
\text { Tinggi } \\
\text { tanaman } \\
\text { per } \\
\text { Diameter } \\
\text { Tajuk }\end{array}$ \\
\hline P1: Kontrol (tanpa perlakuan) & $49.75 \mathrm{c}$ & 4.55 & $1.30 \mathrm{ab}$ & $30.05 \mathrm{~b}$ & 1.66 \\
\hline P2: Retardan saat pindah tanam & $21.00 \mathrm{a}$ & 2.50 & $1.19 \mathrm{a}$ & $18.90 \mathrm{a}$ & 1.05 \\
\hline $\begin{array}{l}\text { P3: Retardan } 1 \text { minggu setelah } \\
\text { pindah tanam }\end{array}$ & $19.15 \mathrm{a}$ & 2.36 & $1.24 \mathrm{ab}$ & $19.50 \mathrm{a}$ & 0.98 \\
\hline $\begin{array}{l}\text { P4: Retardan } 2 \text { minggu setelah } \\
\text { pindah tanam }\end{array}$ & $24.20 \mathrm{a}$ & 2.72 & $1.15 \mathrm{a}$ & $19.75 \mathrm{a}$ & 1.13 \\
\hline $\begin{array}{l}\text { P5 : Pemangkasan pucuk saat pindah } \\
\text { tanam }\end{array}$ & $42.50 \mathrm{~b}$ & 4.03 & $1.28 \mathrm{ab}$ & $30.00 \mathrm{~b}$ & 1.46 \\
\hline $\begin{array}{l}\text { P6 : Pemangkasan pucuk } 1 \text { minggu } \\
\text { setelah pindah tanam }\end{array}$ & $43.35 \mathrm{~b}$ & 4.09 & $1.49 \mathrm{~b}$ & $30.00 \mathrm{~b}$ & 1.52 \\
\hline $\begin{array}{l}\text { P7 : Pemangkasan pucuk } 2 \text { minggu } \\
\text { setelah pindah tanam }\end{array}$ & $42.45 \mathrm{~b}$ & 4.03 & $1.42 \mathrm{ab}$ & $30.00 \mathrm{~b}$ & 1.43 \\
\hline
\end{tabular}


Pada percobaan ini, tinggi pot yang digunakan adalah $14 \mathrm{~cm}$, sehingga tinggi tanaman krisan pot yang ideal adalah $28-35 \mathrm{~cm}$. Pengukuran tinggi tanaman dalam percobaan ini dilakukan dengan cara mengukur tinggi tanaman dari pangkal batang hingga ujung tajuk tanaman. Jika tinggi tanaman diukur mulai dari dasar pot maka tinggi krisan pot kontrol adalah $63.75 \mathrm{~cm}$, tinggi krisan pot perlakuan retardan adalah $33.25-38.15 \mathrm{~cm}$ dan tinggi krisan pot perlakuan pemangkasan pucuk adalah $56.5-57.35 \mathrm{~cm}$. Rasio antara tinggi krisan pot dengan tinggi pot untuk tanaman kontrol adalah 4.55, sedangkan perlakuan retardan adalah 2.36-2.72 dan perlakuan pemangkasan pucuk adalah 4.03-4.09. Mengacu pada kriteria ideal tinggi tanaman krisan pot menurut Kurnia (2017) yaitu 24-35 $\mathrm{cm}$, serta mengacu pada rasio antara tinggi tanaman dengan tinggi pot yang digunakan menurut Ramadhan et al. (2018) yaitu 2-2.5 kali tinggi pot, dapat disimpulkan bahwa tinggi krisan pot yang mendekati kriteria ideal adalah perlakuan retardan dua minggu setelah pindah tanam.

Dari hasil pengamatan terhadap lingkar batang, ternyata pemberian retardan saat pindah tanam maupun dua minggu setelah pindah tanam, menyebabkan ukuran lingkar batangnya lebih kecil secara nyata dibandingkan perlakuan pemangkasan pucuk satu minggu setelah pindah tanam. Hasil penelitian Nazarudin et al. (2007) dengan menggunakan alat mikrograph elektron, menunjukkan bahwa ketebalan jaringan xylem irisan melintang batang tanaman Syzygium campanulatum yang diberi perlakuan paclobutrazol $3.75 \quad \mathrm{~g} \mathrm{~L} \mathrm{~L}^{-1}$ adalah $84.68 \mu \mathrm{m}$ sedangkan pada kontrol adalah $164.63 \mu \mathrm{m}$, artinya terjadi penurunan ketebalan jaringan xylem batang secara nyata sebesar $48.6 \%$ akibat perlakuan paclobutrazol. Menurut Rubiyanti dan Rochayat (2015), waktu yang tepat saat pemberian paclobutrazol akan efektif menghambat pembentukan giberelin atau merangsang kerusakan giberelin sehingga konsentrasi giberelin dalam tanaman menurun, selanjutnya menyebabkan laju pembelahan dan pemanjangan sel menjadi lambat.

Dari hasil pengamatan terhadap diameter tajuk krisan pot, nampak bahwa pemberian retardan menyebabkan diameter tajuk lebih sempit dibandingkan kontrol dan perlakuan pemangkasan pucuk. Tajuk tanaman berkembang karena adanya pertumbuhan pada bagian batang, percabangan, daun maupun tangkai bunga tanaman krisan.
Pemberian retardan diduga menghambat pertumbuhan memanjang diantara berbagai organ tanaman tersebut, sehingga diameter tajuknya menjadi lebih sempit. Hal ini sesuai dengan hasil penelitian Kurnia (2017) pada tanaman krisan White Puma yaitu terjadi penurunan diameter tajuk akibat pemberian retardan.

Kekompakan penampilan krisan pot bisa dilihat dari rasio antara tinggi krisan pot dengan diameter tajuk. Nilai rasio 1.0 menunjukkan krisan pot penampilannya proposional dan kompak. Pada Tabel 1, nilai rasio pada tanaman kontrol adalah 1.66 artinya bahwa tanaman pot tersebut terlihat kurang proporsional dan terkesan kurang kompak. Pemberian retardan dan pemangkasan pucuk ternyata bisa menyebabkan nilai rasio tinggi tanaman per diameter tajuk mendekati angka 1.0. Efek pemberian retardan terlihat menyebabkan tanaman menjadi lebih proporsional antara tinggi dan diameter tajuknya sehingga nampak lebih kompak dibandingkan perlakuan pemangkasan pucuk. Hal ini didukung oleh Abrol et al. (2018) yang menyatakan bahwa pemberian retardan menyebabkan pertumbuhan tanaman krisan lebih kompak dan dedaunan lebih hijau.

Hasil analisis pengamatan jumlah bunga per tanaman, jumlah bunga per pot, diameter kuntum bunga dan rasio jumlah bunga mekar per jumlah bunga per pot disajikan dalam Tabel 2 . Pada Tabel 2, terlihat bahwa jumlah bunga per tanaman dan jumlah bunga per pot meningkat secara nyata pada perlakuan pemangkasan pucuk, baik dibandingkan kontrol maupu perlakuan retardan. Kuntum bunga tanaman krisan muncul pada setiap cabang tanaman sehingga semakin banyak percabangannya bisa menyebabkan semakin banyak kuntum bunganya. Habiba et al. (2012) menyatakan bahwa pemangkasan pucuk menyebabkan berkembangnya cabang baru sehingga memperbanyak jumlah daun serta jumlah kuncup bunga. Hasil penelitian Ona et al. (2015) pada tanaman krisan menunjukkan bahwa dua kali pemangkasan pucuk meningkatkan jumlah bunga tetapi menurunkan tinggi tanaman krisan. Kour (2009) menyatakan bahwa jumlah bunga maksimum dan hasil bunga per hektar terjadi pada perlakuan pemangkasan pucuk setelah 25 hari pindah tanam karena meningkatnya jumlah cabang per tanaman. Selain meningkatkan jumlah bunga per tanaman dan jumlah bunga per pot, ternyata diameter kuntum bunga pada perlakuan pemangkasan pucuk tidak berbeda nyata dibandingkan kontrol. 
Tabel 2. Pengaruh pemangkasan pucuk dan retardan terhadap jumlah bunga per tanaman, jumlah bunga per pot, diameter bunga dan rasio jumlah bunga mekar per jumlah bunga per pot

\begin{tabular}{lcccc}
\hline \multicolumn{1}{c}{ Perlakuan } & $\begin{array}{c}\text { Jumlah } \\
\text { Bunga per } \\
\text { Tanaman }\end{array}$ & $\begin{array}{c}\text { Jumlah } \\
\text { Bunga per } \\
\text { Pot }\end{array}$ & $\begin{array}{c}\text { Diameter } \\
\text { Bunga } \\
(\mathrm{cm})\end{array}$ & $\begin{array}{c}\text { Rasio } \\
\text { Bunga } \\
\Sigma \text { Bunga } \\
\text { per Pot }\end{array}$ \\
\hline P1: Tanpa perlakuan & $5.65 \mathrm{a}$ & $30.28 \mathrm{~b}$ & $6.17 \mathrm{bc}$ & 0.48 \\
P2: Retardan saat pindah tanam & $5.11 \mathrm{a}$ & $19.61 \mathrm{a}$ & $4.83 \mathrm{~b}$ & 0.10 \\
P3: Retardan 1 minggu setelah pindah tanam & $5.58 \mathrm{a}$ & $19.71 \mathrm{a}$ & $4.13 \mathrm{a}$ & 0.11 \\
P4: Retardan 2 minggu setelah pindah tanam & $5.01 \mathrm{a}$ & $23.23 \mathrm{a}$ & $4.75 \mathrm{ab}$ & 0.07 \\
P5 : Pemangkasan pucuk saat pindah tanam & $8.55 \mathrm{~b}$ & $36.63 \mathrm{bc}$ & $6.01 \mathrm{bc}$ & 0.28 \\
$\begin{array}{l}\text { P6: Pemangkasan pucuk 1 minggu setelah } \\
\text { pindah tanam }\end{array}$ & $9.60 \mathrm{~b}$ & $39.68 \mathrm{c}$ & $6.60 \mathrm{c}$ & 0.30 \\
$\begin{array}{l}\text { P7: Pemangkasan pucuk 2 minggu setelah } \\
\text { pindah tanam }\end{array}$ & $9.80 \mathrm{~b}$ & $42.10 \mathrm{c}$ & $6.69 \mathrm{c}$ & 0.21 \\
Keterangan: Angka yang diikuti oleh huruf yang sama pada kolom yang sama tidak berbeda nyata pada Uji BNJ taraf 5\%.
\end{tabular}

Dalam percobaan ini pemberian retardan ternyata menyebabkan jumlah bunga per pot maupun diameter bunga lebih rendah dibandingkan kontrol. Sindhuja et al. (2018) menyatakan bahwa zat pengatur tumbuh digunakan untuk memanipulasi pertumbuhan serta pembungaan tanaman hias. Dalam percobaan ini ternyata efek pemberian retardan berakibat menghambat pembentukan bunga, bahkan efek penghambatan pertumbuhan tersebut masih berlanjut hingga ke fase pertumbuhan kuntum bunga yang berhasil muncul dan menyebabkan ukuran diameter bunga menjadi lebih kecil dibandingkan kontrol.

Analisis nilai rasio antara jumlah kuntum bunga mekar dengan jumlah kuntum bunga per pot pada saat $50 \%$ tanaman kontrol bunganya mekar, bertujuan untuk menggambarkan keserentakan mekarnya bunga krisan dalam pot. Hasil analisis menunjukkan bahwa, nilai rasio antara jumlah bunga mekar dengan jumlah bunga per pot, pada tanaman kontrol lebih lebih tinggi dibandingkan nilai ratio pada perlakuan retardan maupun perlakuan pemangkasan pucuk. Hal ini berarti bahwa baik perlakuan retardan maupun perlakuan pemangkasan pucuk menyebabkan mekarnya bunga krisan dalam pot kurang serentak dibandingkan tanaman kontrol.

\section{KESIMPULAN}

Perlakuan retardan meningkatkan klorofil daun krisan, tanaman menjadi lebih pendek, diameter tajuk lebih kecil, jumlah bunga per pot lebih sedikit, diameter bunga lebih kecil. Pemangkasan pucuk menurunkan tinggi tanaman, meningkatkan jumlah bunga per tanaman dan jumlah bunga per pot. Perlakuan retardan maupun pemangkasan pucuk menyebabkan mekarnya bunga kurang serentak dibandingkan kontrol. Perlakuan retardan menyebabkan penampilan tanaman lebih ideal baik dibandingkan kontrol maupun dibandingkan perlakuan pemangkasan pucuk.

\section{DAFTAR PUSTAKA}

Abrol, A., S.R. Dhiman, A. Qureshi, P. Sharma, S. Sharma. 2018. Effect of growth regulators on potted chrysanthemum (Dendranthema grandiflora Tzvelve)- a revew article. Journal of Emerging Technologies and Innovative Research. 5(8): 486-489.

Datta, S.K.D. 2012. Year round cultivation of garden chrysanthemum (Chrysanthemum morifolium Ramat.) through photoperiodic response. Science and Culture. 78(1-2):71-77. 
Habiba, S.U., M.S. Islam., A.F.M.J. Uddin. 2012. Influence of terminal bud pinching on growth and yield of Chrysanthemum, Chrysanthemum Indicum L. Journal of Bangladesh Academy of Sciences. 36(2): 251-255.

Hayati, N.Q., Nurmalinda., B. Marwoto. 2018. Inovasi teknologi tanaman krisan yang dibutuhkan pelaku usaha. J. Hort. 28(1): 147-162.

Kour, R. 2009. Flowering production as effected by spacing and pinching in Chrysanthemum cv. FLIRT. International Journal of Agricultural Sciences. 5(2): 588-589.

Kurnia, T.I.D. 2017. Morfologis krisan white dan yellow Puma dengan penambahan retardan. Jurnal Biologi dan Pembelajaran Biologi. 2(2): 44-53.

Naidu, J.H., Pashok, R.C. Sekhar, K. Sasikala. 2014. Effect of plant growth retardants and spacings on vegetative growth and flower yield of African marigold (Tagetes erecta L) cv Pusa Narangi Gainda. Intl. J. of Farm Sciences. 4(2): 92-99.

Nazarudin, M.R.A. 2012. Plant growth retardants effect on growth and flowering of potted Hibiscus rosasinensis L. J. Trop. Plant Physiol. 4 (2012): 29-40.

Nazarudin, M.R.A., R.M. Fauzi, F.Y. Tsan. 2007. Effects of Paclobutrazol on the growth and anatomy stems and leaves of Syzygium campanulatum. Journal of Tropical Forest Science. 19(2): 86-91.

Ni'mah, A.N., Sitawati. 2018. Pengaruh konsentrasi Daminozide dan waktu disbudding pada pertumbuhan krisan pot (Chrysanthemum sp.). Jurnal Produksi Tanaman. 6(8): 1671-1676.

Nurmalinda, N.Q. Hayati. 2014. Preferensi konsumen terhadap krisan bunga potong dan pot. J. Hort. 24(4): 363-372.
Nurrahmadani, R., Irawati. 2017. Pengaruh waktu aplikasi 2,2-Dimethylhydrazide terhadap pertumbuhan dan pembungaan tanaman krisan (Chrysanthemum morifolium Ramat). J.Agroteknologi Universitas Andalas. 1(1): 36-43.

Ona, A.F., T. Taufique, M.Z.K. Roni, N.J. Jui, A.F.M.J. Uddin. 2015. The influence of pinching on growth and yield of snowball chrysanthemum. IJBSSR. 3(3): 174-178.

Pobudkiewicz, A. 2014. Effect of growth retardant on some morphological and physiological traits of chrysanthemum. Pol. J. Natur. Sc. 29(4): 291-306.

Pratomo, A.G., K.B. Andri. 2013. Aspek sosial ekonomi dan potensi agribisnis bunga krisan di Kabupaten Pasuruan Jawa Timur. J. Hort. Indonesia. 4(2): 70-76.

Ramadhan, F.S.A., Setyono, E.D.S. Nugroho. 2018. Pengaruh kerapatan tanam dan konsentrasi pupuk NPK pada krisan Pot (Chrysanthemum morifolium Ramat). Jurnal Agronida. 4(1): 29-36.

Rubiyanti, N., Y. Rochayat. 2015. Pengaruh konsentrasi paclobutrazol dan waktu aplikasi terhadap mawar batik (Rosa hybrida L.). J. Kultivasi. 14 (1): 59-64.

Sajid, M., N.U. Amin, H. Khan, A. Rehman, I. Hussain. 2016. Influence of various photoperiods on enhancing the flowering time in chrysanthemum (Chrysanthemum morifolium). Intl. Journal of Biosciences. 8(2): 115-123.

Sindhuja, M., V.M. Prasad, V. Koradakera. 2018. Effect of different plant growth regulators and their levels on floral yield and vase life of China Aster [Callistephus chinensis (L.) Nees] cv. Shashank. Int. J. Curr. Microbiol. App. Sci. 7(1): 3391-3396.

Suhadi, I., Nurhidayati, B.A. Sharon. 2017. Efektifitas retardan sintetik terhadap pertumbuhan dan masa pajang bunga matahari (Hellianthus annus L.). Agrifor. 16(2): 219-228. 